\title{
Unprotected mothers and infants breastfeeding in public amenities during the COVID-19 pandemic
}

\author{
Xue Wang ${ }^{1} \cdot$ Jie Han $^{1}$ (1) $\cdot$ Eric Lichtfouse ${ }^{2,3}$ (1)
}

Published online: 21 July 2020

C) Springer Nature Switzerland AG 2020

The outbreak of the coronavirus disease, named COVID19 , has quickly spread at the global scale. On July 11, 2020, there have been a total of 12,286,264 confirmed cases worldwide (WHO 2020a). Recent studies related to air pollution have reported that the novel coronavirus could survive in the ambient air for several hours and potentially transmit through aerosols, especially in enclosed indoor environments with limited social distancing and poor ventilation (Morawska and Milton 2020; Sharma et al. 2020; WHO 2020b). When breastfeeding in public amenities, mothers can wear masks or cloth face coverings to protect themselves from respirable virus carriers in the air, while their infants cannot wear any respiratory protection to avoid direct exposure to the indoor air. With respect to the airborne transmission of COVID19 , breastfeeding in public amenities therefore represents a blind spot in the current regulatory guidelines and risk mitigation efforts (CDC 2020; NHC 2020; WHO 2020c). Here we outline the common issues in the current design of lactation facilities and the use of other public amenities by breastfeeding mothers, as a timely reminder on the potential risks to breastfeeding mothers and unprotected infants during the current pandemic (Fig. 1).

Breastfeeding is the most effective way to ensure the health and survival of infants. For newborns, breastmilk is the ideal food because it is safe, nutritious and contains antibodies (WHO 2020d). While the COVID-19 has been detected in human breastmilk (Groß et al. 2020), there

Jie Han

jiehan@xjtu.edu.cn

1 Department of Environmental Science and Engineering, Xi' an Jiaotong University, Xi' an 710049, Shaanxi, People's Republic of China

2 Aix-Marseille University, CNRS, IRD, INRAE, Coll France, CEREGE, 13100 Aix en Provence, France

3 State Key Laboratory of Multiphase Flow in Power Engineering, Xi' an Jiaotong University, Xi' an 710049, Shaanxi, People's Republic of China has been no evidence to date suggesting transmission to infants via breastmilk, but this appears more and more likely because a recent report has evidenced transplacental transmission to the fetus followed by neurological manifestations (Vivanti et al. 2020). The World Health Organization (WHO) has recommended mothers with confirmed or suspected COVID-19 infection to continue breastfeeding with necessary precautions (WHO 2020e). In the same vein, the American Academy of Pediatrics (AAP) recommends mothers to consider extending the duration of breastfeeding to supply antibodies to their infants or toddlers during the current pandemic (AAP 2020). Overall, breastfeeding appears to be a good practice to maintain the health and reduce the risks for infants during the current pandemic, yet there is a need for sufficient lactation rooms in the public space.

Once a privileged facility, lactation rooms have become more common as a public amenity for lactating mothers and their infants. For instance, the US federal laws require that employers with over 50 employees must provide a placeother than a bathroom-for employees to give breastmilk to infants (NCSL 2020). Some states require shopping malls, airports and public service centers to provide areas for breastfeeding (NCSL 2020). A recent survey shows that only $77 \%$ of US airports display information on accesses to lactation rooms (Lee et al. 2019). In China, the National Health Commission requires that baby care rooms with an area no less than $10 \mathrm{~m}^{2}$ should be provided at transportation hubs, commercial centers, hospitals, tourist attractions and other public places either wider than $10,000 \mathrm{~m}^{2}$ or with more than 10,000 visitors per day (NHC 2016). The commission also recommends employers to provide lactation rooms under the same conditions. As a result, in September 2018, there were about 286,000 organizations across the country which had provided lactation rooms in their workplace in China (Anonymous 2019). Overall, the number of lactation rooms has clearly increased, but their design and location may not be optimized. 
Fig. 1 Risk of infants' exposure to airborne pathogens and pollutants in a public lactation room. The number of lactation rooms have increased in the public space, yet many issues remain to be solved, such as inadequate area, location near toilets, poor ventilation and lack of air temperature control

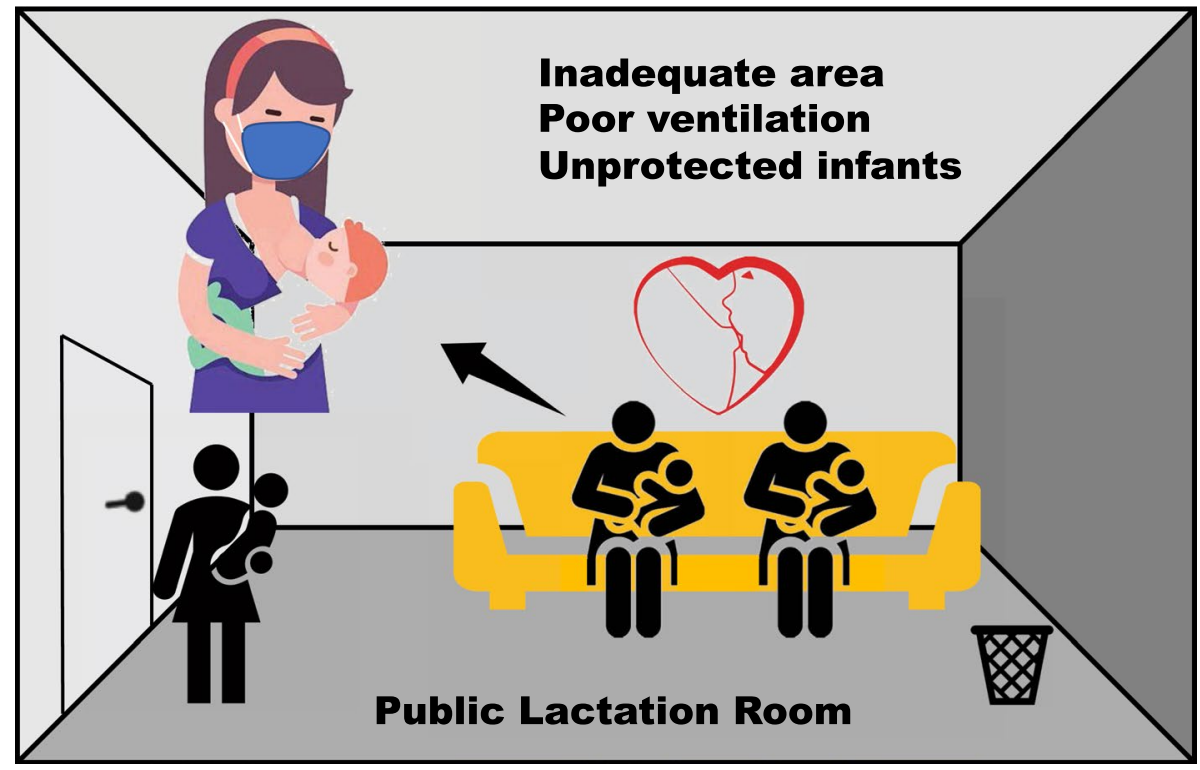

Several issues have been evidenced in recently set-up public amenities for breastfeeding. For instance, many public lactation rooms are located in corners with an inadequate design, often as small, enclosed spaces with windowless walls. This is dangerous for the heath of mothers and babies because enclosed spaces such as schools and beauty salons are known to concentrate air pollutants (de Gennaro et al. 2014; Rogula-Kopiec et al. 2018). A survey of 105 lactation facilities in US university campuses revealed that over $80 \%$ of the designated spaces were structurally enclosed, and only about $40 \%$ of those places had in-room control of air temperature (Henry-Moss et al. 2019). Worse, only 8\% of the busiest US airport fulfilled the minimum requirements of space and facilities for a public lactation room (Haight and Ortiz 2014). In China, while surveys are scarce, many lactation rooms and baby care rooms were found to be inadequate in sizes and ventilation (PMM 2018). For example, a survey of 60 public locations in three major Chinese cities disclosed that only $24 \%$ of locations provided an adequate area of more than $10 \mathrm{~m}^{2}$ for baby care (Teng 2017). Moreover, $70 \%$ of those rooms were located next to public toilets, and only $35 \%$ of the rooms had good ventilation. This is a serious health issue because Zhu et al. (2001) found severe contamination in indoor air by bacteria in baby care rooms at a hospital, resulting in an overall low compliance rate of $40 \%$ versus the national standard. In conclusion, many lactation facilities are inappropriate in terms of location, ventilation, temperature control and health security. Mothers may therefore be tempted to find other locations.

Some mothers opt to breastfeed in public toilets as a secure place shielded from public views and free of intrusion by the opposite sex (Sha 2017). Such practice, which is commonly perceived as breastfeeding in public, threatens the unprotected infants because human wastes carry a myriad of pathogens (Haight and Ortiz 2014; Spurles and Babineau 2010; Datta et al. 2020). Indeed, pathogens could be transmitted not only by airborne transport of respiratory droplets, but also via the fecal-oral route from toilet flushing or poor hygiene. This is very likely because Knowlton et al. (2018) found that the atmospheric concentrations of fine particles, below $0.3 \mu \mathrm{m}$, and bioaerosols both increased significantly after toilet flushing in hospitals. Moreover, those aerosols formed a prolonged and uniform suspension in air with no obvious attenuation within $30 \mathrm{~min}$ after toilet flushing. In the same vein, $81 \%$ of aerosols and $78 \%$ of surfaces of public toilets located in an office building and a hospital contained respiratory or enteric viruses including the adenovirus, the Torque teno virus and the norovirus GII (Verani et al. 2014). Overall, breastfeeding in public toilets presents high risk of contamination, which might be aggravated by the fast breathing of infants.

Infants should be exclusively breastfed for six months and then continue to be fed with breastmilk and complementary food at least until 12 months (AAP 2012; WHO 2020f). For infants within six months of age, the general recommendation is $8-12$ times during $24 \mathrm{~h}$, each feeding lasting 10-20 min (CDC 2018; Littleton and Richardson 2019). Most importantly, infants younger than 12 months have much faster respiratory rates than adults, generally in the range 30-50 breaths per minute compared with 12-18 by adults (Fleming et al. 2011). While being breastfed, the infant's nose and mouth are exposed to the ambient air, and the infant maintains a faster breathing rate for the suckswallow-breath coordination. This suggests that infants are at elevated risks of exposure to airborne pathogens in public amenities during breastfeeding. 
The COVID-19 episode has also accentuated the risk induced by poor ventilation. Indeed, regulators and utility operators have discouraged the use of air conditioning in confined public spaces to prevent the spread of COVID-19 by air circulation (CPMI 2020; WHO 2020g). This creates a dilemma for facilities lacking natural ventilation such as public lactation rooms. Furthermore, COVID-19 remained viable and infectious in aerosols for three hours at ambient conditions (van Doremalen et al. 2020). Higher rates of viral transmission were observed in confined space when persons were in contact with COVID-19 infected patients (Zhao et al. 2020). In addition, breastfeeding in public toilets or family restrooms increases the risk of fecal-oral transmission of COVID-19 (Xiao et al. 2020). High viral loads of COVID19 have been detected in human feces, even in asymptomatic individuals and recovered patients several weeks after their respiratory samples became clear (Han et al. 2020; Wu et al. 2020; Zhang et al. 2020). Direct evidence was provided on June 25, 2020, by the Beijing Center for Disease Prevention and Control, which announced that two persons became infected after using a public toilet that was later tested positive (Li 2020). This was known as the first confirmed case of COVID-19 transmission in public toilet environments in China. Overall, the risk of virus transmission to breastfeeding mothers and infants in public amenities is high. What could we suggest to improve their safety?

There is actually no viable means of protecting an infant's respiration while being breastfed. To this date, no specific guideline has been published to mitigate such risks during the current pandemic (CDC 2020; NHC 2020). Given that many public breastfeeding amenities are small and poorly ventilated, we suggest that, when not in use, doors should be regularly opened to allow natural ventilation, while standard cleaning and disinfection protocols for public spaces are followed (CDC 2020). When breastfeeding in a public facility, mothers should wear respiratory protection to protect themselves and others who may use the same facility concurrently or shortly after. Mothers should use the facility alone during the current pandemic to reduce the risk of cross-infection between users. In light of the known risks of fecal-oral transmission of COVID-19, breastfeeding in public toilets is not recommended during the current pandemic. Instead, mothers should be encouraged to breastfeed in open areas where good ventilation and physical distancing can be achieved. Efforts should also be put in improving the design of public lactation rooms, including the provision of adequate areas and emergency ventilation facilities. Safety windows should be installed well above the average height of adults with exhaust fans in operation to maintain good ventilation in the room without compromising the privacy of users. More generally, air pollution and the associated health risks should be alleviated both indoors and outdoors using any means (Yu 2014, 2019; Feng and Zheng 2019;
Wang et al. 2020). Here, recent results suggest that the use of essential oils, a traditional medicine, may offset the deleterious effect of airborne particulate matter (Kfoury et al. 2016).

Funding This work was funded by the "Young Talent Support Plan" of Xi' an Jiaotong University.

\section{Compliance with ethical standards}

Conflict of interest Authors declare that they have no conflict of interest in this work.

\section{References}

AAP American Academy of Pediatrics (2012) Breastfeeding and the use of human milk. Pediatrics 129(3):e827-e841. https://doi. org/10.1542/peds.2011-3552

AAP American Academy of Pediatrics (2020) Breastfeeding guidance: post hospital discharge for mothers or infants with suspected or confirmed SARS-CoV-2 infection. https://services.aap.org/en/ pages/2019-novel-coronavirus-covid-19-infections/clinical-guida nce/breastfeeding-guidance-post-hospital-discharge/. Accessed 11 July 2020

Anonymous (2019) Unions have set up 286,000 rest and lactation rooms across the country. Chin Work 06:12

CDC Centers for Disease Control and Prevention (2018) How much and how often to breastfeed, https://www.cdc.gov/nutrition/Infan tandToddlerNutrition/breastfeeding/how-much-and-how-often .html. Accessed 11 July 2020

CDC Centers for Disease Control and Prevention (2020) Reopening guidance for cleaning and disinfecting public spaces, workplaces, businesses, schools, and homes. https://www.cdc.gov/coronaviru s/2019-ncov/community/reopen-guidance.html. Accessed 11 July 2020

CPMI China Property Management Institute (2020) Technical guidelines for operation and management of air conditioning and ventilation systems during epidemic period. https://www.ecpmi.org.cn/ NewsInfo.aspx?NewsID=9520. Accessed 11 July 2020

de Gennaro G, Dambruoso PR, Loiotile AD et al (2014) Indoor air quality in schools. Environ Chem Lett 12:467-482. https://doi. org/10.1007/s10311-014-0470-6

Datta S, Rajnish KN, Samuel MS et al (2020) Metagenomic applications in microbial diversity, bioremediation, pollution monitoring, enzyme and drug discovery. A review. Environ Chem Lett 18:1229-1241. https://doi.org/10.1007/s10311-020-01010-z

Feng R, Zheng HJ (2019) Evidence for regional heterogeneous atmospheric particulate matter distribution in China: implications for air pollution control. Environ Chem Lett 17:1839-1847. https:// doi.org/10.1007/s10311-019-00890-0

Fleming S, Thompson M, Stevens R et al (2011) Normal ranges of heart rate and respiratory rate in children from birth to 18 years of age: a systematic review of observational studies. Lancet 377(9770):1011-1018. https://doi.org/10.1016/S0140 -6736(10)62226-X

Groß R, Conzelmann C, Müller JA et al (2020) Detection of SARSCoV-2 in human breastmilk. Lancet 395(10239):1757-1758. https ://doi.org/10.1016/S0140-6736(20)31181-8 
Haight M, Ortiz J (2014) Airports in the United States: Are they really breastfeeding friendly? Breastfeed Med 9(10):515-519. https:// doi.org/10.1089/bfm.2014.0112

Han MS, Seong MW, Kim N et al (2020) Viral RNA load in mildly symptomatic and asymptomatic children with COVID-19, Seoul. Emerg Infect Dis. https://doi.org/10.3201/eid2610.202449

Henry-Moss D, Lee J, Benton K et al (2019) An exploration of lactation facilities and planning in U.S. higher education campuses. Breastfeed Med 14(2):121-127. https://doi.org/10.1089/bfm.2018.0198

Kfoury M, Borgie M, Verdin A et al (2016) Essential oil components decrease pulmonary and hepatic cells inflammation induced by air pollution particulate matter. Environ Chem Lett 14(3):345-351. https://doi.org/10.1007/s10311-016-0572-4

Knowlton SD, Boles CL, Perencevich EN et al (2018) Bioaerosol concentrations generated from toilet flushing in a hospital-based patient care setting. Antimicrob Resist Infect Control 7:16. https ://doi.org/10.1186/s13756-018-0301-9

Lee JS, Ganzert A, Jackson C (2019) The traveling mother: Navigating, visualizing and utilizing lactation spaces in US airports. Build Environ 164:106323. https://doi.org/10.1016/j.buildenv.2019.106323

Li JH (2020) Solved: Beijing couple infected in a public toilet. https:// www.nbd.com.cn/articles/2020-06-25/1450480.html. Accessed 11 July 2020

Littleton K, Richardson JH (2019) Breastfeeding FAQs: how much and how often. https://kidshealth.org/en/parents/breastfeed-often.html. Accessed 11 July 2020

Morawska L, Milton DK (2020) It is time to address airborne transmission of COVID-19. Clin Infect Dis. https://doi.org/10.1093/ $\mathrm{cid} / \mathrm{ciaa} 939$

NCSL National Conference of State Legislatures (2020) Public laws pp 111-148 and pp 111-152: Consolidated Print-478. https://www. ncsl.org/research/health/breastfeeding-state-laws.aspx. Accessed 11 July 2020

NHC National Health Commission of the P.R. China (2016) Guidelines on accelerating the construction of facilities for mothers and infants. https://www.nhc.gov.cn/cms-search/xxgk/getMa nuscriptXxgk.htm?id=7de90996a6ec4ffa83dd538591c8e7bd. Accessed 11 July 2020

NHC National Health Commission of the P.R. China (2020) Education handbook on COVID-19 (2nd edition). https://www.nhc.gov. cn/xcs/kpzs/202003/179cd85afbc74692b5c97eae9fe9ff4d.shtml Accessed 11 July 2020

PMM Perfect Maternity Magazine (2018) How desperate is it to go out and find a clean lactation room. https://www.sohu.com/a/24803 9175_99976636. Accessed 11 July 2020

Rogula-Kopiec P, Rogula-Kozłowska W, Pastuszka JS et al (2018) Air pollution of beauty salons by cosmetics from the analysis of suspensed particulate matter. Environ Chem Lett 17:551-558. https ://doi.org/10.1007/s10311-018-0798-4

Sha Q (2017) Breast-feeding mothers face a policy dilemma: many breast-feed in public toilets. https://health.huanqiu.com/artic le/9CaKrnK4vfT. Accessed 11 July 2020

Sharma VK, Jinadatha C, Lichtfouse E (2020) Environmental chemistry is most relevant to study coronavirus pandemics. Environ Chem Lett 18:993-996. https://doi.org/10.1007/s10311-020-01017-6

Spurles PK, Babineau J (2010) A qualitative study of attitudes toward public breastfeeding among young Canadian men and women. J Hum Lact 27(2):131-137. https://doi.org/10.1177/0890334410 390044

Teng Q (2017) The investigation on the space design of the baby care room in public places, a Dissertation submitted for the Master's Degree, South China University of Technology

van Doremalen N, Bushmaker T, Morris DH et al (2020) Aerosol and surface stability of SARS-CoV-2 as compared with SARS-CoV-1. N Engl J Med 382:1564-1567. https://doi.org/10.1056/NEJMc 2004973
Verani M, Bigazzi R, Carducci A (2014) Viral contamination of aerosol and surfaces through toilet use in health care and other settings. Am J Infect Control 42(7):758-762. https://doi.org/10.1016/j. ajic.2014.03.026

Vivanti AJ, Vauloup-Fellous C, Prevot S et al (2020) Transplacental transmission of SARS-CoV-2 infection. Nat Commun 11:3572. https://doi.org/10.1038/s41467-020-17436-6

Wang LQ, Li MY, Yu S et al (2020) Unexpected rise of ozone in urban and rural areas, and sulfur dioxide in rural areas during the coronavirus city lockdown in Hangzhou, China: implications for air quality. Environ Chem Lett. https://doi.org/10.1007/s10311-020-01028-3

WHO World Health Organization (2020a) Coronavirus disease (COVID-19) pandemic-Number at a glance. https://www.who. int/emergencies/diseases/novel-coronavirus-2019. Accessed 11 July 2020

WHO World Health Organization (2020b) Transmission of SARSCoV-2: implications for infection prevention precautions. https ://www.who.int/news-room/commentaries/detail/transmissionof-sars-cov-2-implications-for-infection-prevention-precautions. Accessed 11 July 2020

WHO World Health Organization (2020c) Cleaning and disinfection of environmental surfaces in the context of COVID-19. https:// www.who.int/publications/i/item/cleaning-and-disinfection-ofenvironmental-surfaces-inthe-context-of-covid-19. Accessed 11 July 2020

WHO World Health Organization (2020d) Breastfeeding overview. https://www.who.int/health-topics/breastfeeding\#tab=tab_1. Accessed 11 July 2020

WHO World Health Organization (2020e) Breastfeeding and COVID19. https://www.who.int/emergencies/diseases/novel-coron avirus-2019/question-and-answers-hub/q-a-detail/q-a-on-covid -19-and-breastfeeding. Accessed 11 July 2020

WHO World Health Organization (2020f) Recommendations on breastfeeding. https://www.who.int/health-topics/breastfeed ing\#tab=tab_2. Accessed 11 July 2020

WHO World Health Organization (2020g) Preparedness, prevention and control of COVID-19 in prisons and other places of detention. https://www.euro.who.int/_data/assets/pdf_file/0019/43402 6/Preparedness-prevention-and-control-of-COVID-19-in-priso ns.pdf. Accessed 11 July 2020

Wu Y, Guo C, Tang L et al (2020) Prolonged presence of SARS-CoV-2 viral RNA in faecal samples. Lancet Gastroenterol Hepatol 5:434 435. https://doi.org/10.1016/S2468-1253(20)30083-2

Xiao F, Tang MW, Zheng XB et al (2020) Evidence for gastrointestinal infection of SARS-CoV-2. Gastroenterology 158(6):1831-1833. https://doi.org/10.1053/j.gastro.2020.02.055

Yu SC (2014) Water spray geoengineering to clean air pollution for mitigating haze in China's cities. Environ Chem Lett 12:109-116. https://doi.org/10.1007/s10311-013-0444-0

Yu SC (2019) Fog geoengineering to abate local ozone pollution at ground level by enhancing air moisture. Environ Chem Lett 17:565-580. https://doi.org/10.1007/s10311-018-0809-5

Zhang TQ, Cui XJ, Zhao X et al (2020) Detectable SARS-CoV-2 viral RNA in feces of three children during recovery period of COVID-19 pneumonia. J Med Virol 92(7):909-914. https://doi. org/10.1002/jmv.25795

Zhao H, Li BS, Xia Y et al (2020) Investigation of transmission chain of a cluster COVID-19 cases. Chin J Dis Control Prev 41:E064. https://doi.org/10.3760/cma.j.cn112338-20200227-00198

Zhu RY, Zhang YM, Hu MJ et al (2001) Air microbiological pollution and its influencing factors in hospital nursing room. Chin J Dis Control Prev 01:21-22

Publisher's Note Springer Nature remains neutral with regard to jurisdictional claims in published maps and institutional affiliations. 